\title{
Definição e Monitoração de Objetivos de Software Alinhados ao Planejamento Estratégico
}

\author{
Andrea Oliveira Soares Barreto, Ana Regina Rocha \\ COPPE/UFRJ - Programa de Engenharia de Sistemas e Computação \\ Caixa Postal 68511 - CEP: 21945-970 - Rio de Janeiro - RJ \\ ansoares@cos.ufrj.br, darocha@cos.ufrj.br
}

\begin{abstract}
This work presents an approach to define and monitor software goals, which are related to software products and processes and have to be aligned with the strategic planning of the organization. It is expected that these goals will guide the deployment of software improvements, including the implementation of higher maturity levels through the use of statistical process control. Our approach includes strategic planning activities, the translation of this planning into organizational plans that define software goals and also project planning activities, always aiming to promote the alignment with business goals. We present an example of the use of our approach.
\end{abstract}

Resumo: Este trabalho apresenta uma proposta para definição e monitoração de objetivos de software, que são objetivos relacionados aos produtos e processos de software e devem ser alinhados ao planejamento estratégico da organização. Espera-se que esses objetivos orientem a implantação de melhorias de software, incluindo a implementação de altos níveis de maturidade através do controle estatístico dos processos. A abordagem proposta abrange desde o planejamento estratégico, passando pela tradução deste planejamento em planos organizacionais que definam os objetivos de software, até o planejamento dos projetos, de forma a promover o alinhamento aos objetivos de negócio. Um exemplo de uso da abordagem proposta é descrito.

\section{Introdução}

A crescente demanda por produtos de software com altos níveis de qualidade tem forçado as organizações a buscarem alternativas para a melhoria de seus produtos. No entanto, a busca pela melhoria somente pelo desejo de melhorar, sem preocupação em contribuir para os objetivos de negócio da organização, pode não melhorar a posição da organização no mercado. Para ser efetiva, a melhoria de software deve apoiar as ações que atendam aos objetivos de negócio da organização [Conradi e Fuggetta, 2002].

Modelos de maturidade como o CMMI-DEV [Chrissis et al., 2006] e o MRMPS [Softex, 2007] estabelecem o conceito de objetivos de qualidade e desempenho de processo, que englobam objetivos e requisitos para a qualidade de produtos, qualidade de serviço, e desempenho de processos. Esses objetivos devem sempre ser baseados nos objetivos de negócio da organização, e têm enorme importância, principalmente em níveis mais altos de maturidade, onde são utilizados em diversos contextos, tais como (i) seleção e implantação de melhorias inovadoras, que podem ser feitas visando aumentar as chances de alcançar esses objetivos; (ii) seleção de subprocessos críticos para controle estatístico; (iii) gerência estatística de projetos, que verifica continuamente o alcance dos objetivos; (iv) análises de causa raiz, que podem ser iniciadas para investigar as razões de não se atingir algum objetivo; entre outros. Assim, ao iniciar os esforços para alcance de níveis mais altos de maturidade, a definição desses objetivos é 
muito importante, pois guiarão outras práticas que deverão ser realizadas. No entanto, acredita-se que mesmo para organizações que não estejam buscando níveis mais altos de maturidade, iniciar, nos níveis mais baixos, pela definição de objetivos relacionados a software e que, se atendidos, contribuam para o alcance dos objetivos de negócio, seja de grande importância. Até mesmo, para que a organização tenha maior facilidade, no futuro, para alçar vôos mais altos em relação à maturidade de seus processos.

Nesta abordagem usamos o conceito de "objetivo de software", semelhante ao objetivo de qualidade e desempenho, porém, não necessariamente um objetivo quantitativo, como costuma ser o foco em altos níveis de maturidade. Assim, em níveis mais baixos de maturidade, um objetivo de software pode não ser quantitativo, enquanto em níveis mais altos é recomendável que seja. Um objetivo de software é uma decomposição de um objetivo de negócio (e, portanto, é alinhado ao seu planejamento estratégico) que é mensurável e diz respeito apenas a produtos ou processos de software.

Definir objetivos de software alinhados aos objetivos de negócio e ao planejamento estratégico da organização pode não ser simples. Mesmo nos principais modelos de melhorias de processos de software, os objetivos de negócio não estão facilmente relacionados às melhorias de software a serem implementadas [Becker et al., 2008]. Além disso, o processo de traduzir os objetivos estratégicos em ações é uma tarefa difícil, pois é preciso considerar um grande número de possibilidades em um cenário onde normalmente há pouca informação estruturada [Ren et al., 2006]. Assim, elaborar o planejamento estratégico e traduzi-lo em objetivos, ações e planos mais detalhados para serem executados nos projetos, atendendo aos objetivos de negócio, pode ser complexo, principalmente se não houver um procedimento que indique os passos a serem executados. Outro aspecto a ser considerado é ter objetivos mensuráveis, de forma a constantemente monitorar seu alcance. Sem um acompanhamento contínuo, a definição dos objetivos tende a se tornar inócua e não será possível saber se estão ou não sendo alcançados nem a distância entre os resultados atuais e os esperados. Segundo Wang et al. [2006], para uma organização de software, monitorar seu desempenho atual com relação ao planejado é tão importante quanto estimar prazo e custo.

Assim, várias questões se apresentam para uma organização, ao definir objetivos de software alinhados aos negócio permitindo a monitoração de seu alcance, tais como: Como definir estratégias para atender aos objetivos de negócio? Como considerar as dependências entre os objetivos definidos? Como considerar necessidades da organização e necessidades específicas dos projetos? Como possibilitar a medição e gerência quantitativa desses objetivos? Como possibilitar uma revisão desses objetivos a partir do feedback dos projetos ou a partir de mudanças nos objetivos de negócio?

Neste contexto, este trabalho apresenta uma abordagem para definição e monitoração de objetivos de software que apóia atividades desde o planejamento estratégico, passando pela definição dos objetivos de software, pelo planejamento dos projetos de software alinhados aos objetivos de negócio, até a monitoração destes planos durante a execução dos projetos. A abordagem proposta descreve os passos a serem realizados para: (i) a definição dos objetivos de negócio; (ii) o planejamento estratégico a partir desses objetivos; (iii) o detalhamento do planejamento estratégico no que diz respeito aos produtos e processos de software em um plano organizacional que defina objetivos de software e considere o controle estatístico dos processos de software e a medição de software; (iv) o planejamento dos projetos de software alinhados ao 
planejamento organizacional; e (v) a monitoração e a revisão dos planejamentos dos projetos, organizacional e estratégico. Pelo fato de a abordagem ser muito ampla e de o espaço ser limitado, não foi possível descrever todos os seus detalhes, tendo os autores optado por descrever uma visão geral das etapas a serem realizadas.

Este artigo contém em cinco seções, incluindo esta introdução. A seção 2 apresenta uma breve revisão sobre planejamento estratégico e objetivos de software. A seção 3 descreve a proposta para definição e monitoração dos objetivos de software com uma estratégia que vai desde o planejamento estratégico até o controle estatístico de processos e a medição nos projetos. A seção 4 relata uma experiência de uso da abordagem e a seção 5 apresenta as conclusões e perspectivas futuras deste trabalho.

\section{Planejamento Estratégico, Definição e Monitoração de Objetivos}

Cada organização pode ser analisada sob três diferentes níveis hierárquicos [Rezende e Abreu, 2001; Chiavenato, 2000]:

- Institucional ou Estratégico: nível mais elevado da organização envolvendo aqueles que definem os objetivos empresariais ou estratégicos ou, ainda, objetivos de negócio da organização. Neste nível é elaborado o planejamento estratégico relacionado aos objetivos estratégicos, que são de longo prazo, e às ações para alcançá-los, que afetam a organização como um todo.

- Gerencial ou Tático: nível intermediário responsável pela comunicação entre os níveis estratégico e operacional, respondendo também pela administração do nível operacional. Neste nível é elaborado o planejamento tático onde são definidos os objetivos táticos, isto é, objetivos de médio ou curto prazo e as ações para alcançá-los, que geralmente afetam somente parte da organização.

- Operacional: é a base da organização estando relacionado à execução das tarefas. Neste nível é elaborado o planejamento operacional onde são definidas as tarefas a serem executadas.

No nível mais alto da organização é elaborado o planejamento estratégico onde são definidas as atribuições do nível tático, que por sua vez, elabora um planejamento para execução de suas atribuições, delegando tarefas ao nível operacional, que também planeja a execução dessas tarefas e as executa. No contexto das organizações maiores, a área de tecnologia da informação pode ser vista como um tipo de organização de software que está contextualizada em uma corporação. Assim, corporações elaboram o seu planejamento estratégico, porém, muitas vezes faz-se necessário um planejamento estratégico específico da área de tecnologia da informação.

Com o intuito de direcionar os esforços relacionados à tecnologia da informação de modo que apóiem os objetivos e estratégias da organização, foi desenvolvido o COBIT - Control Objectives for Information Technology [IT Governance Institute, 2007]. O COBIT é um framework que descreve um conjunto de objetivos de negócio genéricos e um conjunto objetivos de TI, também genéricos, relacionados aos objetivos de negócio. Apesar de ser um conjunto de boas práticas relacionadas à gerência, à medição e ao controle de objetivos de negócio e de TI, o COBIT não apóia em detalhes a elaboração do planejamento estratégico.

A literatura apresenta alguns trabalhos de apoio ao planejamento estratégico. No contexto deste trabalho vale destacar um modelo de planejamento estratégico de 
sistemas de informação que apóia o processo decisório, incorporando aspectos de aprendizagem organizacional como forma de incrementar a viabilidade de implementação do plano, proposto por Audy [2000]. Esta proposta apóia somente o planejamento estratégico, não se preocupando com o desdobramento deste planejamento em planos táticos relacionados aos produtos e processos de software.

No contexto das organizações que desenvolvem produtos de software, os objetivos táticos podem ou não estar relacionados a software. Quando relacionados a software, estes objetivos podem ser denominados objetivos de software da organização. Já o nível operacional pode ser organizado em projetos de software e então o planejamento operacional é composto do planejamento dos projetos de software. Um projeto pode definir objetivos específicos, denominados objetivos do projeto.

O planejamento elaborado em cada nível precisa ser acompanhado através de indicadores que tratem informações quantitativas e qualitativas sobre o desempenho da organização [Rezende e Abreu, 2001]. Para permitir a análise de cada indicador de forma a detectar se o comportamento da organização está em conformidade com o comportamento esperado, também é importante a definição de metas. Para apoiar a definição de indicadores alinhados ao planejamento estratégico de uma organização, Kaplan e Norton [1996] propõem o Balanced Score Card - BSC como um framework para descrever, implementar e gerenciar a estratégia de uma organização em todos os seus níveis, relacionando objetivos, iniciativas e medidas para esta estratégia. $\mathrm{O}$ framework propõe uma análise baseada nas medições do desempenho através de objetivos e indicadores em quatro perspectivas: (i) Financeira, (ii) Clientes, (iii) Processos Internos, e (iv) Aprendizado e Crescimento.

A monitoração dos objetivos definidos depende de dados que permitam compreender o desempenho da organização. Em organizações de software, esses dados precisam estar relacionados ao software. BASILI et al. [2007] propõem o $\mathrm{GQM}^{+}$ Strategies para alinhamento das estratégias de negócio à medição de software. A abordagem contém os passos: (i) Selecionar objetivos de negócio corretos; (ii) Selecionar o conjunto correto de estratégias; (iii) Selecionar objetivos de software corretos; (iv) Selecionar cenários corretos; (v) Selecionar objetivos de medição corretos; (vi) Derivar questões e métricas com GQM [Basili et al., 1994]. A abordagem foca a medição e não trata o planejamento estratégico, nem o controle estatístico de processos.

Apesar de existirem trabalhos que de alguma forma tratam o planejamento estratégico, a definição e monitoração dos objetivos definidos nos três níveis hierárquicos, o controle estatístico de processos e a medição de software, não foi encontrada na literatura uma abordagem que trate todas essas questões de forma integrada. Acredita-se que uma abordagem que apóie desde o planejamento estratégico até o controle estatístico dos processos e a medição, mantendo o foco nos produtos e processos de software, porém visando o alcance dos objetivos estratégicos seja de grande ajuda, contribuindo para a definição de objetivos de software mais realistas.

\section{Definição e Monitoração de Objetivos de Software Alinhados ao Planejamento Estratégico}

Para definir objetivos de software alinhados aos objetivos de negócio da organização, é preciso primeiro elaborar o planejamento estratégico, que fornecerá as diretrizes para a definição dos objetivos de software alinhados ao que for definido no nível estratégico. 
A abordagem se inicia no nível estratégico com a caracterização da organização, seguida do planejamento estratégico como base para o nível tático, como mostra a Figura 1. A partir da execução e monitoração no nível tático, o nível estratégico é monitorado e caso seja detectado um desvio, é importante analisá-lo para determinar se é preciso executar ações corretivas ou se o planejamento estratégico deve ser revisado.

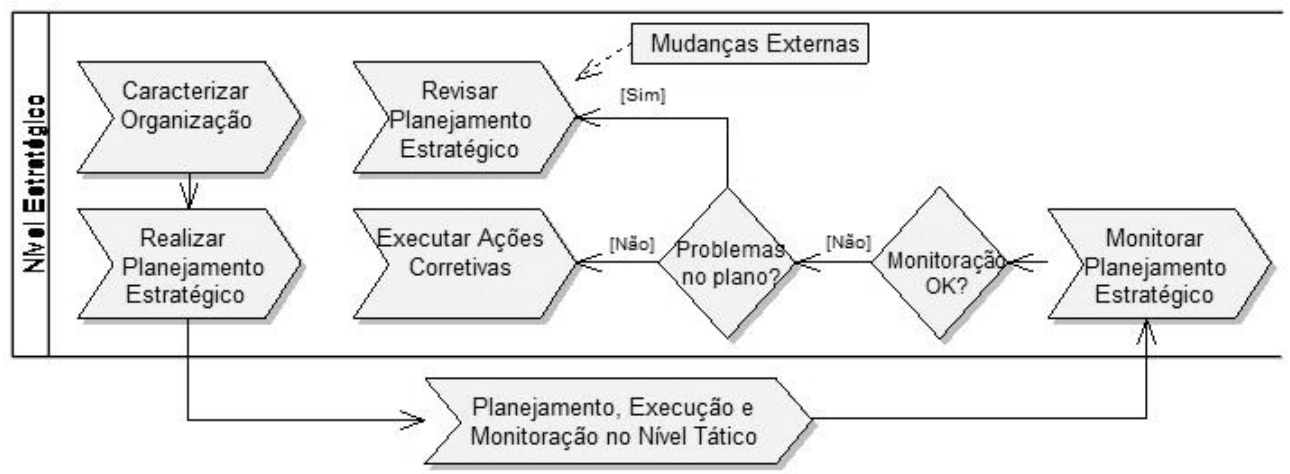

Figura 1. Contexto de definição, monitoração e revisão do planejamento estratégico

$\mathrm{Na}$ caracterização da organização o escopo do planejamento e os intervalos de curto, médio e longo prazo que serão considerados são determinados, considerando características específicas da organização, do mercado de atuação e de seus negócios. Um exemplo de intervalos de curto, médio e longo prazo para uma organização de pequeno porte seria 6,12 e 24 meses, respectivamente.

Uma das formas de facilitar o foco e a atenção nas áreas críticas para a organização é definir perspectivas que foquem individualmente em algum ponto crítico e que estejam relacionadas entre si, permitindo a devida atenção a cada área crítica, de forma balanceada. Nesta abordagem, a caracterização da organização inclui, ainda, a identificação das perspectivas que são importantes para a organização. Por exemplo, as perspectivas sugeridas pelo BSC ou outras mais adequadas à organização. A caracterização da organização é necessária, pois serve de orientação para o início do planejamento estratégico delineando os prazos esperados para percepção dos resultados do planejamento e as perspectivas a serem consideradas.

Nas próximas seções descrevemos a abordagem proposta em cada um dos níveis e para a monitoração dos objetivos. Ao longo da descrição são apresentados exemplos descrevendo informações fictícias, porém, úteis à compreensão.

\subsection{Planejamento Estratégico}

Esta abordagem descreve o planejamento estratégico pelas etapas ilustradas na Figura 2.

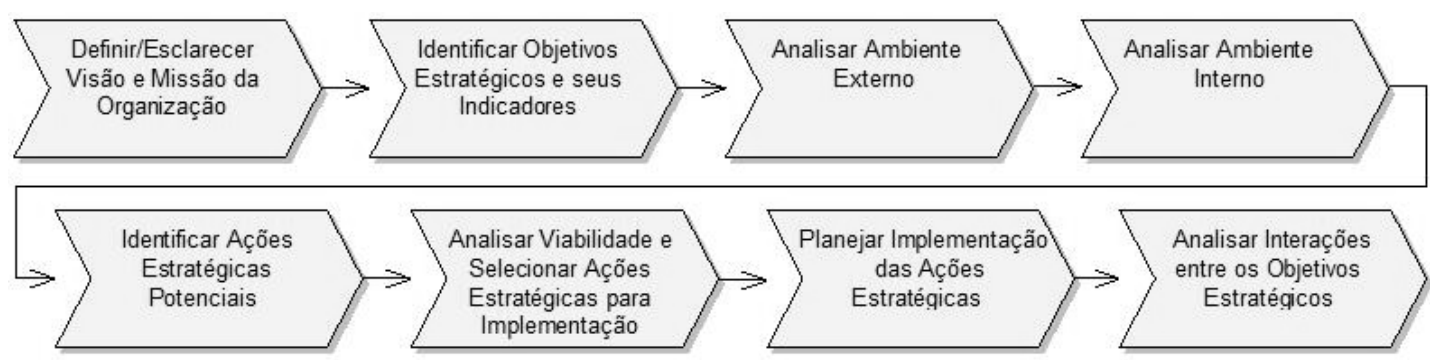

Figura 2. Etapas do Planejamento Estratégico 
A primeira etapa é a definição da missão e visão da organização, que devem orientar a definição dos objetivos estratégicos da organização. A missão de uma organização representa sua finalidade enquanto a visão descreve o que ela gostaria de ser dentro de um determinado período de tempo [Chiavenato, 2000].

Logo após, os objetivos estratégicos e seus indicadores devem ser definidos. Quando definidos isoladamente, esses objetivos podem não descrever claramente as intenções da organização desviando a atenção das áreas críticas do negócio. Por isso, cada objetivo estratégico é relacionado a alguma perspectiva, dentre aquelas que foram definidas para organização e, para assegurar o balanceamento entre essas perspectivas, deve existir pelo menos um objetivo para cada perspectiva identificada. A identificação do objetivo estratégico deve descrever as seguintes informações: (i) Ação: ação esperada, tais como: aumentar, diminuir, manter, melhorar; (ii) Objeto da ação: o que deve ser afetado pela ação, por exemplo: faturamento, lucro, satisfação dos clientes, qualidade; e (iii) Perspectiva: perspectiva na qual o objetivo deve ser analisado.

Para padronizar a documentação dos objetivos estratégicos e demais informações descritas a cada etapa da proposta garantindo a descrição de todas as informações necessárias, foram desenvolvidos modelos de documentos como um padrão para documentação das informações definidas a cada etapa. Os modelos facilitam o uso da proposta, pois podem ser usados como instrumento de apoio à execução da abordagem. A Tabela 1 mostra objetivos estratégicos, descritos no padrão proposto.

Tabela 1. Exemplo de objetivos estratégicos

\begin{tabular}{|l|l|l|l|l|l|}
\hline Ação: & Aumentar & Objeto da Ação: & Satisfação dos Clientes & Perspectiva: & Clientes \\
\hline Ação: & Melhorar & Objeto da Ação: & $\begin{array}{l}\text { Qualidade dos Produtos } \\
\text { de Software }\end{array}$ & Perspectiva: & $\begin{array}{l}\text { Processos } \\
\text { Internos }\end{array}$ \\
\hline
\end{tabular}

Além de identificar os objetivos estratégicos, é importante planejar também como eles serão monitorados permitindo o acompanhamento contínuo desses objetivos. Para isso, continuando o planejamento estratégico, a cada objetivo definido são associados indicadores, permitindo a detecção de desvios e a execução de ações corretivas. Com o intuito de possibilitar um acompanhamento mais pró-ativo, permitindo a detecção de possíveis desvios antes mesmo que eles ocorram, a definição de cada indicador detalha a meta em três faixas de valores: (i) Faixa aceitável: valores considerados na meta e sem risco de desvio próximo; (ii) faixa de risco: valores considerados dentro da meta, porém, que sinalizam um risco de desvio próximo; e (iii) Faixa inaceitável: valores considerados fora da meta indicando um desvio real.

Dependendo do indicador definido, pode ser necessário definir três metas considerando o resultado esperado no curto, médio e longo prazo. A definição dessas metas pode ser de forma ad-hoc, baseada em dados históricos ou usando simulações para analisar possíveis valores. Uma organização de alta maturidade deve basear-se no conhecimento sobre a capacidade de seus processos para determinar as metas.

O planejamento estratégico considera as intenções da organização descritas através dos objetivos estratégicos, porém, para facilitar o alcance desses objetivos é importante analisar os ambientes externo e interno à organização de modo a identificar forças que podem contribuir ou dificultar o alcance dos objetivos. A análise do ambiente externo se dá com a identificação de fatores ou tendências externos à organização que podem representar ameaças ou oportunidades. Além disso, é necessário analisar os 
possíveis impactos relacionados a cada fator, considerando que um fator pode causar um impacto positivo representando uma oportunidade e este mesmo fator também pode causar um impacto negativo representado uma ameaça. $\mathrm{O}$ ambiente interno também deve ser analisado, permitindo uma avaliação de seus principais pontos fortes e pontos fracos à luz dos objetivos estratégicos identificados.

Como os objetivos estratégicos tendem a ser amplos e visar o longo prazo, o detalhamento desses objetivos em ações estratégicas, isto é, ações que se executadas tendem a facilitar o alcance dos objetivos estratégicos, se faz necessário. As ações estratégicas potenciais devem visar o alcance dos objetivos estratégicos usando as oportunidades e pontos fortes identificados e tratando as ameaças e pontos fracos percebidos nas análises externa e interna. Esta etapa deve ser executada preferencialmente com a participação de representantes do nível tático. A definição de uma ação estratégica deve descrever a ação, o valor, quando aplicável, o objeto da ação, o percentual de contribuição esperado para o objetivo estratégico relacionado e indicar se a ação está relacionada a software. A Tabela 2 mostra possíveis ações estratégicas.

Tabela 2. Exemplo de ações estratégicas

\begin{tabular}{|l|c|l|c|c|}
\hline \multicolumn{4}{|c|}{ Objetivo Estratégico Relacionado: } & Aumentar a satisfação dos clientes \\
\hline \multicolumn{3}{|c|}{ Ação Estratégica } & Contribuição & Software \\
\hline Reduzir & $20 \%$ & Preço dos produtos de software & $40 \%$ & Sim \\
\hline Aumentar & - & Qualidade dos produtos de software & $30 \%$ & Sim \\
\hline Reduzir & $10 \%$ & Tempo de entrega & $20 \%$ & Sim \\
\hline Melhorar & - & Atendimento ao cliente & $10 \%$ & Não \\
\hline
\end{tabular}

Após a identificação das ações estratégicas potenciais, deve-se então analisar a viabilidade de cada uma e selecionar aquelas que serão de fato implementadas. Para cada ação estratégica selecionada deve-se planejar a implementação definindo: (i) Prioridade: prioridade da ação estratégica em relação às demais ações; (ii) Responsável: responsável pela implementação da ação (nível tático); (iii) Recursos: recursos financeiros disponíveis para a implementação; e (iv) Indicadores: indicadores para monitoração da ação estratégica com metas associadas. Esses indicadores e suas metas são definidos tal como a definição dos indicadores associados aos objetivos estratégicos.

Para finalizar o planejamento estratégico é necessário analisar os objetivos estratégicos, as ações estratégicas e os indicadores definidos para identificar e documentar possíveis interações entre os objetivos estratégicos. Cada interação deve ser descrita com as seguintes informações: (i) Objetivo estratégico relacionado: Objetivo estratégico relacionado ao objetivo que está sendo analisado; e (ii) Tipo: tipo da interação. Uma interação entre objetivos pode ser dos seguintes tipos: interdependência qualitativa direta, interdependência qualitativa inversa ou interdependência quantitativa.

\subsection{Planejamento Tático}

Nesta abordagem, o planejamento estratégico dá origem a ações estratégicas planejadas e atribuídas aos responsáveis no nível tático da organização e, neste nível, cada responsável realiza um planejamento tático para implementação das ações estratégicas sob sua responsabilidade. A Figura 3 apresenta a visão geral do planejamento tático sendo a primeira etapa realizar o planejamento deste nível que serve como base para o planejamento operacional. A partir dos dados de execução e monitoração no nível operacional, o planejamento tático é monitorado e caso seja detectado algum desvio, é importante analisar o problema para determinar se é necessário executar ações 
corretivas ou se o planejamento tático precisa ser revisado. Os dados de execução no nível tático também são usados no nível estratégico conforme descrito na seção anterior.

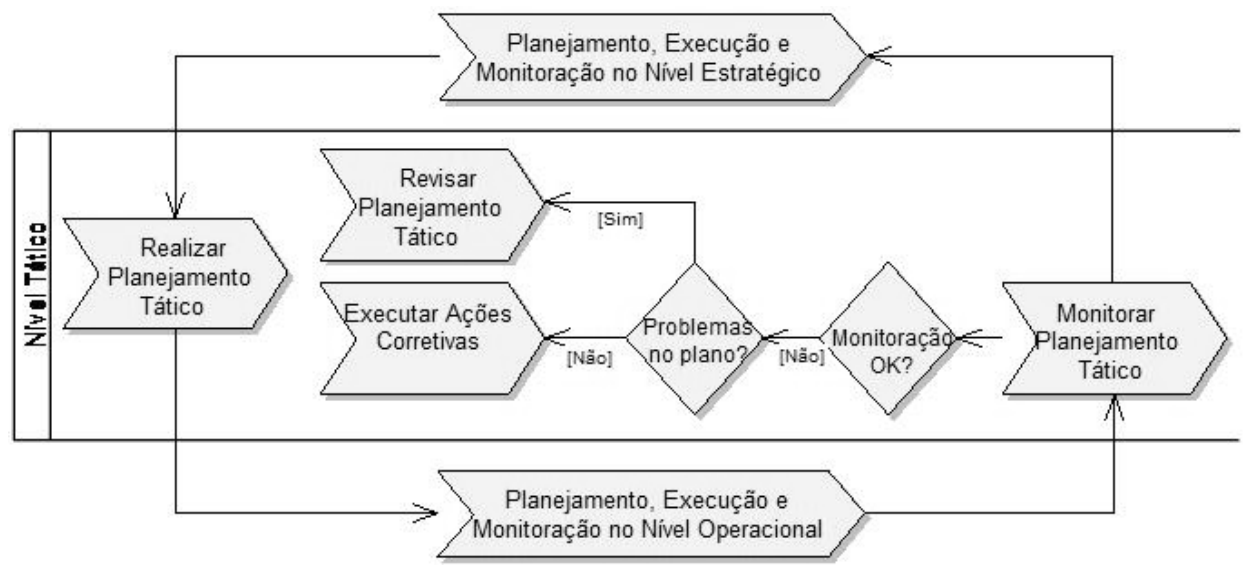

Figura 3. Contexto de definição, monitoração e revisão do planejamento tático

Como as ações estratégicas são definidas ainda no nível estratégico, no nível tático pode ser necessário detalhá-las de modo a torná-las mais facilmente gerenciáveis por este nível. O planejamento tático se inicia, então, com o detalhamento dessas ações estratégicas em objetivos táticos. Nesta abordagem, o planejamento tático é composto das etapas mostradas na Figura 4.

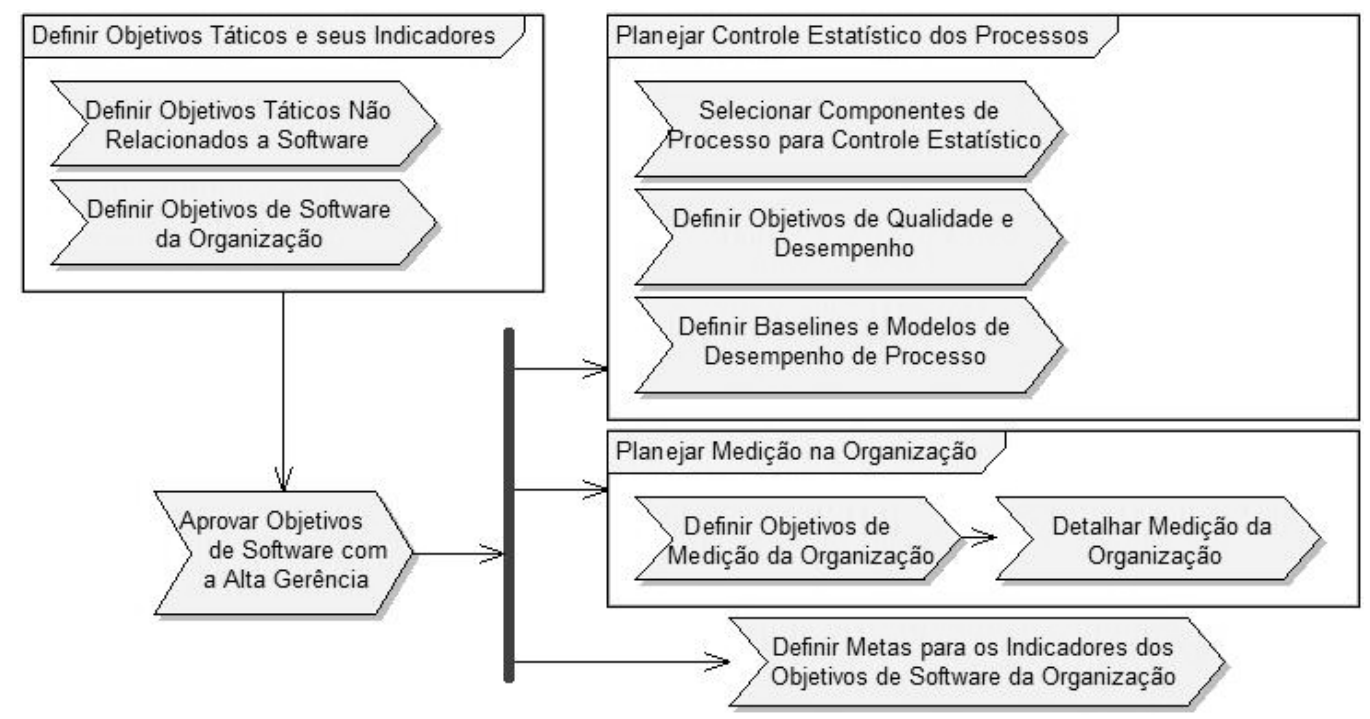

Figura 4. Etapas do Planejamento Tático

No planejamento tático, cada setor responsável deve identificar os objetivos táticos da organização relacionados às suas ações estratégicas que orientarão a implementação dessas ações. Para ilustrar, uma ação estratégica relacionada à melhoria no atendimento ao cliente pode ser de responsabilidade do setor comercial enquanto uma ação relacionada à qualidade dos produtos de software pode ser atribuída à equipe de desenvolvimento de software da organização.

Neste trabalho somente os objetivos táticos relacionados aos produtos e processos de software, denominados objetivos de software da organização, são detalhados. Porém, para permitir a monitoração adequada dos objetivos estratégicos, é recomendável identificar os objetivos táticos não relacionados a software e associar 
indicadores de monitoração. A definição de um objetivo tático não relacionado a software descreve a ação, o objeto da ação, o valor, quando aplicável, o percentual de contribuição para a ação estratégica relacionada e a interação com outros objetivos táticos, que é descrita de forma semelhante às interações entre os objetivos estratégicos.

Para facilitar o acompanhamento dos objetivos de software da organização e permitir maior visibilidade dos resultados, este trabalho propõe a definição de objetivos de software da organização de médio prazo, isto é, que devem ser alcançados no período considerado de médio prazo para a organização. Esses objetivos de médio prazo devem ser detalhados em objetivos de software da organização de curto prazo. Esse detalhamento permite a definição de pequenos marcos, através dos objetivos que devem ser alcançados no curto prazo, que podem ser acompanhados mais freqüentemente, podendo inclusive indicar uma necessidade de revisão dos objetivos de médio prazo. Periodicamente o planejamento tático será revisado e então alguns objetivos de software que eram de médio prazo podem se tornar objetivos de curto prazo. Para ilustrar, uma organização poderia ter como objetivo de software de médio prazo implementar o nível F do modelo de maturidade MR-MPS e no curto prazo, implementar o nível G.

A definição dos objetivos de software de médio e curto prazo descreve: a ação, o valor, quando aplicável, o objeto da ação, o percentual de contribuição para a ação estratégica relacionada, se o objetivo definido é de médio prazo, ou a contribuição para o objetivo de médio prazo, se o objetivo definido é de curto prazo. As interações com outros objetivos de médio ou curto prazo são descritas de forma similar às interações entre os objetivos estratégicos. A Tabela 3 ilustra possíveis objetivos de software.

Tabela 3. Exemplo de objetivos de software da organização

\begin{tabular}{|c|c|c|c|c|}
\hline \multicolumn{3}{|c|}{ Ação Estratégica Relacionada: } & \multicolumn{2}{|c|}{ Aumentar a qualidade dos produtos de software } \\
\hline \multicolumn{4}{|c|}{ Objetivos de Software da Organização } & Contribuição \\
\hline Reduzir & $10 \%$ & & dade de defeitos no produto & $60 \%$ \\
\hline Implantar & - & & s de maturidade de processos & $40 \%$ \\
\hline
\end{tabular}

Para permitir o acompanhamento dos objetivos definidos, os indicadores associados a cada um dos objetivos de software de médio e curto prazo são definidos de forma similar à definição dos indicadores associados aos objetivos estratégicos.

A definição dos objetivos de software de médio prazo e o detalhamento em objetivos de software de curto prazo podem envolver decisões importantes para a organização que necessitem da aprovação da alta gerência. Sendo assim, após a definição desses objetivos pode ser necessário apresentá-los à alta gerência garantindo a aprovação e o comprometimento. Esta etapa pode não ser necessária, dependendo da formalidade entre os níveis hierárquicos da organização, do grau de autonomia do nível tático ou mesmo da participação da alta gerência na definição desses objetivos.

Os objetivos de software da organização são usados para orientar as melhorias relacionadas a produtos e processos de software da organização. Uma organização de alta maturidade, segundo modelos de maturidade [Chrissis et al., 2006; Softex, 2007], precisa implementar melhorias com base no conhecimento sobre comportamento de seus processos, sendo esse conhecimento adquirido através do controle estatístico dos processos. A proposta deste trabalho também se aplica às organizações que estejam buscando ou já possuam altos níveis de maturidade, pois apóia o planejamento do controle estatístico dos processos, como parte do planejamento tático. 
O controle estatístico dos processos demanda tempo e acrescenta custos à organização e, por isso, não precisa ser aplicado a todos os processos da organização. A etapa de planejamento do controle estatístico dos processos se inicia, então, com a seleção dos componentes de processo (subprocessos), que poderão ser controlados estatisticamente, dentre aqueles que compõem os processos da organização. Essa seleção deve ser baseada nos objetivos de software da organização definidos, dentre outras considerações. A partir dos componentes de processo selecionados, deve-se identificar os objetivos de qualidade e desempenho da organização e analisar o comportamento desses componentes, com base nesses objetivos e nas medições existentes. Esse conhecimento deve ser documentado através da definição de baselines de desempenho, que caracterizam resultados reais obtidos anteriormente ao se executar o processo descrevendo o comportamento esperado. Os modelos de desempenho de processo que relacionam atributos dos processos controlados estatisticamente e que podem ser usados para prever resultados, também devem ser definidos. Esta etapa de planejamento do controle estatístico dos processos pode não ser realizada, caso a organização ainda não possua maturidade para controlar estaticamente seus processos nem esteja buscando alcançar a alta maturidade de seus processos.

Independentemente de a organização adotar o controle estatístico de seus processos, a monitoração de cada um dos objetivos definidos é fortemente relacionada às medições realizadas nos projetos e na organização e, se a organização controla estatisticamente seus processos, a medição de software se torna ainda mais importante. Por isso, o planejamento da medição na organização faz parte do planejamento tático, sendo executada em paralelo com o planejamento do controle estatístico dos processos.

A etapa de planejamento da medição consiste em definir objetivos de medição alinhados aos objetivos de software da organização e então derivar medidas, detalhando o planejamento da medição na organização, descrevendo quais medidas são coletadas e como coletá-las e analisá-las. A organização pode derivar novos objetivos de medição ou identificar os objetivos de medição dentre os objetivos de software já definidos. A literatura apresenta algumas propostas para derivar medidas a partir de objetivos como o GQM [Basili et al., 1994] e o GQ(I)M [Park et al., 1996].

A monitoração dos objetivos de software da organização se dá através dos indicadores associados a esses objetivos, conforme descrito na etapa de definição desses objetivos. Porém, as metas para esses indicadores devem ser definidas ou revisadas ao final do planejamento tático, pois o controle estatístico dos processos e a medição na organização podem influenciar essas metas. Então, para concluir o planejamento tático relativo aos produtos e processos de software, é necessário definir metas para os indicadores associados aos objetivos de software definidos. A definição dessas metas é semelhante à definição das metas dos indicadores associados aos objetivos estratégicos.

\subsection{Planejamento dos Projetos}

Nesta abordagem, o planejamento operacional é realizado a partir dos dados do planejamento tático, conforme a visão geral exibida na Figura 5, que ilustra a execução dos projetos no nível operacional, sendo o planejamento dos projetos a primeira etapa. Após o planejamento, cada projeto é então executado e monitorado. Caso seja detectado algum desvio, é importante analisá-lo para determinar se é necessário executar ações corretivas ou se o planejamento dos projetos precisa ser revisado. Os dados de execução dos projetos também são usados no nível tático conforme descrito na seção anterior. 


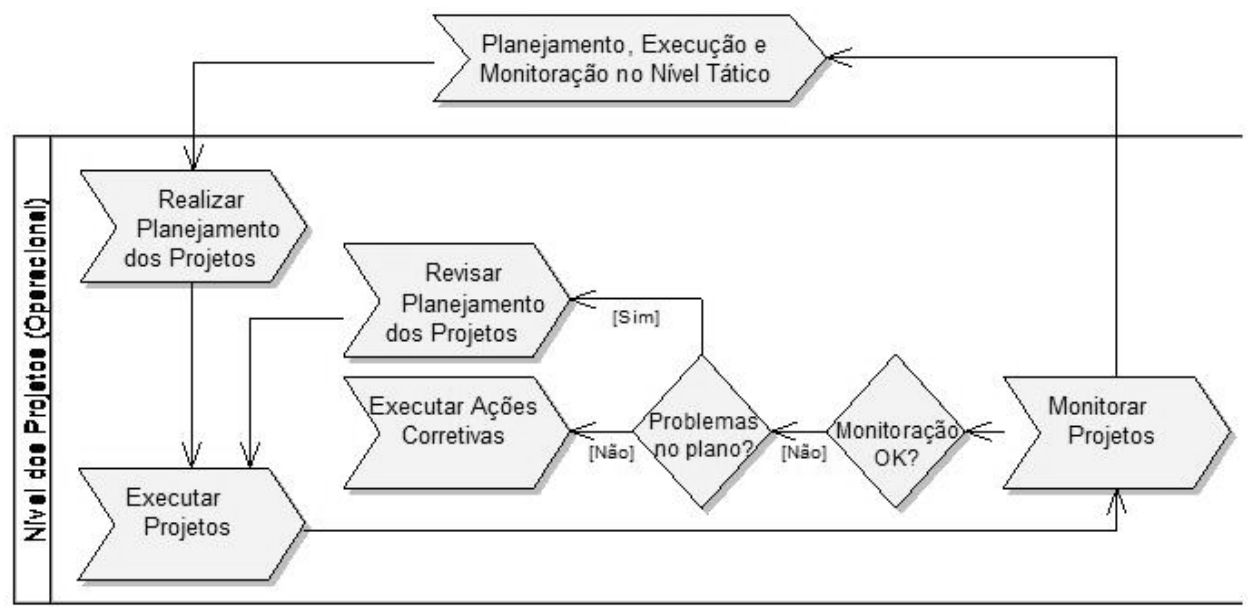

Figura 5. Contexto de definição, monitoração e revisão do planejamento operacional

O planejamento do projeto envolve várias etapas, porém, o foco deste trabalho é o planejamento relacionado aos objetivos do projeto, ao controle estatístico de processos e à medição. A Figura 6 apresenta as etapas do planejamento do projeto com este foco.

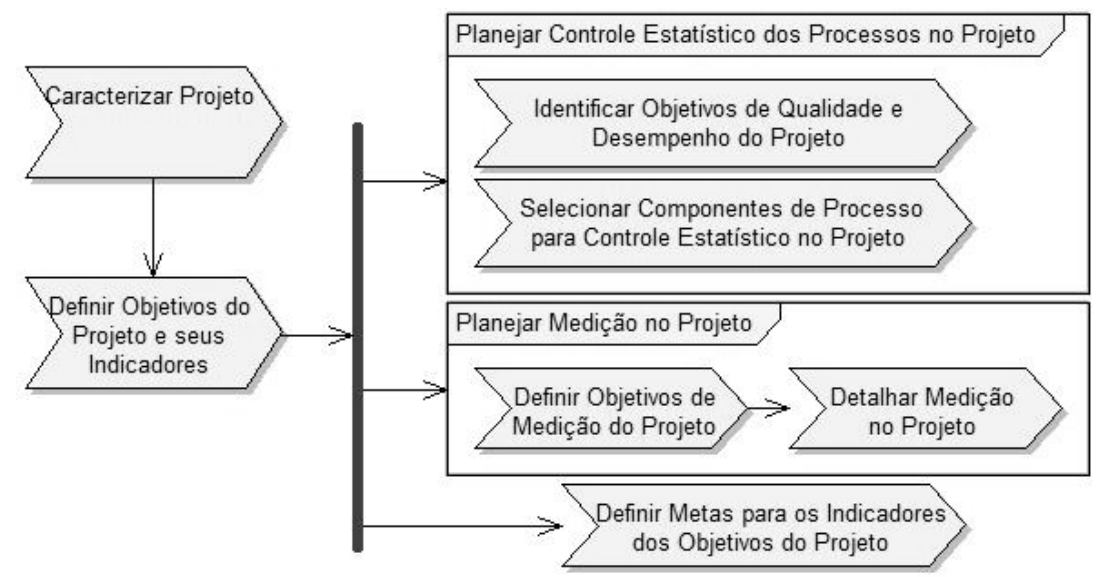

Figura 6. Etapas do Planejamento dos Projetos

Cada projeto possui características específicas que precisam ser consideradas. Assim, o planejamento de um projeto se inicia com sua caracterização, que define, entre outras coisas, seu percentual de contribuição para a organização. Essa informação é importante para determinar o alcance dos objetivos táticos e estratégicos.

Os projetos possuem seus objetivos, aqui denominados objetivos do projeto, que inicialmente são identificados dentre os objetivos de software da organização buscando aqueles que são aplicáveis ao projeto. Para assegurar o alinhamento dos projetos aos objetivos táticos, que por sua vez estão alinhados aos objetivos estratégicos da organização, a princípio todos os objetivos de software de curto prazo da organização devem ser considerados objetivos do projeto, exceto em situações especificas onde algum objetivo não seja aplicável e, neste caso, uma justificativa deve ser formalizada.

A definição dos objetivos do projeto é importante, pois também considera as necessidades específicas dos projetos e seus requisitos podendo originar novos objetivos do projeto, independentemente dos objetivos de software da organização. Desta forma, a implementação dos objetivos de software da organização é assegurada nos projetos, mas esta não restringe os projetos, permitindo que as necessidades específicas não tratadas 
pelos objetivos da organização sejam atendidas. Cada novo objetivo do projeto deve descrever a ação, o valor, quando aplicável, o objeto da ação e as interações com outros objetivos do projeto definidas tal como as interações entre os objetivos estratégicos. A monitoração dos objetivos do projeto ocorre através de indicadores associados a cada objetivo. Para exemplificar, a Tabela 4 mostra possíveis objetivos de um projeto.

Tabela 4. Exemplo de objetivos de um projeto

\begin{tabular}{|l|c|l|c|}
\hline \multicolumn{3}{|c|}{ Objetivos do Projeto } & Específico \\
\hline Reduzir & $10 \%$ & Densidade de defeitos no produto & Não \\
\hline Implantar & - & Modelos de maturidade de processos & Não \\
\hline Garantir & - & Tempo de resposta máximo do produto de 5 segundos & Sim \\
\hline
\end{tabular}

Caso a organização tenha adotado o controle estatístico dos processos, planejado no nível tático, cada projeto precisa planejar como controlar estatisticamente os processos durante a execução do projeto. O planejamento do controle estatístico dos processos no projeto consiste em inicialmente identificar dentre os objetivos de qualidade e desempenho da organização e os objetivos do projeto, quais serão os objetivos de qualidade e desempenho do projeto. Se necessário, novos objetivos do projeto podem ser definidos e identificados como objetivos de qualidade e desempenho do projeto. Uma vez que o controle estatístico não precisa ser adotado em todos os processos executados no projeto, o próximo passo é selecionar os componentes de processo que serão controlados estatisticamente no projeto. Essa seleção é orientada pelos objetivos de qualidade e desempenho do projeto e pelos componentes de processo selecionados para controle estatístico na organização.

Independentemente de o projeto controlar estatisticamente os processos executados, a monitoração de cada um dos objetivos do projeto é realizada através da medição. Então, a etapa de planejamento da medição no projeto faz parte do planejamento do projeto, sendo executada em paralelo com o planejamento do controle estatístico dos processos. A etapa de planejamento da medição no projeto consiste em identificar os objetivos de medição do projeto e as medidas que serão coletadas.

Para concluir o planejamento dos projetos, as metas para os indicadores associados aos objetivos do projeto precisam ser definidas ou revisadas, verificando a consistência entre essas metas e os objetivos de qualidade e desempenho do projeto.

\subsection{Monitoração dos Objetivos Estratégicos, de Software e dos Projetos}

Nesta abordagem, a monitoração dos objetivos definidos em cada nível se dá através do acompanhamento dos indicadores associados aos objetivos. Assim, a cada coleta de uma medida relacionada a algum desses indicadores, novos valores para os indicadores são calculados e novas coletas são registradas. Da mesma forma, caso um indicador que teve uma nova coleta registrada faça parte da composição de outros indicadores, novos valores também são calculados para esses indicadores.

A monitoração nos três níveis depende diretamente da definição de indicadores adequados, isto é, indicadores de monitoração de objetivos do nível tático devem ser calculados a partir dos indicadores dos objetivos do nível operacional e, da mesma forma, indicadores do nível estratégico devem usar os indicadores do nível tático. Essa relação entre os indicadores permite que uma nova coleta para um indicador do nível operacional dispare uma nova coleta dos níveis superiores e, conseqüentemente, uma análise desses indicadores. Assim, caso uma nova coleta em um projeto específico afete 
o alcance dos objetivos dos níveis superiores, essa ameaça será imediatamente percebida através do impacto dessa coleta no cálculo dos indicadores dos níveis acima.

A cada nova coleta para um indicador associado a um objetivo estratégico, tático ou do projeto, é feita uma análise considerando as metas definidas em faixas de valores aceitáveis, de risco e inaceitáveis (como descrito na seção 3.1). Caso a análise indique um valor é aceitável, nada é feito. Se a análise indicar um valor na faixa de risco, ações preventivas são executadas para evitar que o desvio ocorra. Por fim, se a análise indicar um valor inaceitável, ações corretivas são executadas para corrigir o desvio detectado.

\section{Planejamento Estratégico e Tático no LENS}

Para avaliar a viabilidade da abordagem proposta, ela foi executada no contexto da área de qualidade do Laboratório de Engenharia de Software (LENS) da COPPE/UFRJ. O LENS já foi avaliado com sucesso segundo o nível E do MR-MPS, e atualmente está iniciando esforços visando a alta maturidade, inclusive com o objetivo de ser avaliado em um futuro próximo, segundo este mesmo modelo, porém no nível A. Ao iniciar essa preparação para a alta maturidade, a necessidade de se ter um planejamento estratégico foi identificada pela alta gerência e, esta proposta foi então executada, com o objetivo de se obter um planejamento estratégico que orientasse as melhorias a serem implementadas focando no alcance da alta maturidade na organização. Vale destacar que o LENS não havia elaborado um planejamento estratégico anteriormente.

Essa execução se mostrou uma excelente oportunidade para avaliar a abordagem, por contar com alunos de mestrado, doutorado e doutores que além de serem experientes na academia, também possuem larga experiência na indústria. Além disso, enquanto alguns participantes nunca haviam participado da elaboração de um planejamento estratégico, outros já tinham passado por essa experiência várias vezes.

O planejamento estratégico foi elaborado com a participação dos níveis estratégico e tático do LENS e como instrumento de apoio foram usados os modelos definidos, como descrito na seção 3.1. Para elaborar o planejamento estratégico, foram realizadas reuniões onde cada etapa do planejamento estratégico segundo a abordagem proposta foi executada, começando com a caracterização da organização e a definição da missão e visão da organização seguindo com a execução dos demais passos. A Tabela 5 apresenta dois dos cinco objetivos estratégicos que foram identificados para o LENS. Foram identificados oito fatores externos, três pontos fortes e dois pontos fracos que impactavam os objetivos estratégicos. À luz dessa análise externa e interna foram planejadas dezoito ações estratégicas sendo quatro delas relacionadas a software.

Tabela 5. Alguns objetivos estratégicos definidos para o LENS

\begin{tabular}{|l|l|l|l|l|l|}
\hline Ação: & Atingir & Objeto da Ação: & $\begin{array}{l}\text { Nível A de maturidade } \\
\text { do MR-MPS }\end{array}$ & Perspectiva: & $\begin{array}{l}\text { Processos } \\
\text { Internos }\end{array}$ \\
\hline Ação: & Garantir & Objeto da Ação: & Excelência da Equipe & Perspectiva: & $\begin{array}{l}\text { Aprendizado e } \\
\text { Crescimento } \\
\text { Profissional }\end{array}$ \\
\hline
\end{tabular}

Após a conclusão do planejamento estratégico, a execução da abordagem continuou com a elaboração do planejamento tático, que contou com a participação da alta gerência. No nível tático, as ações estratégicas relacionadas a software deram origem aos objetivos de software da organização que servem como orientação para o 
planejamento do controle estatístico. Porém, foi percebido que antes de iniciar o planejamento do controle estatístico dos processos de software é necessário tratar alguns problemas já identificados e que podem prejudicar o alcance dos objetivos de software definidos. Foi feita então uma análise das necessidades de informação e dos problemas relacionados aos objetivos de software e então foram definidos planos de ação para tratar os problemas identificados. Atualmente estes planos de ação estão em execução, e somente após a conclusão destes planos será possível continuar o planejamento tático e então analisar e selecionar os componentes de processo para o controle estatístico.

Foi interessante perceber que durante o planejamento estratégico já foi possível identificar problemas que poderiam afetar o alcance dos objetivos estratégicos e, antes mesmo de concluir as etapas do planejamento estratégico, decisões foram tomadas pelo nível estratégico e notificadas à organização. A reflexão sobre a visão da organização e seus objetivos estratégicos confrontada com a realidade percebida com as análises externa e interna já foi capaz de identificar situações críticas para o alcance da visão e orientar a tomada de decisões para viabilizar o alcance dos objetivos estratégicos.

Do planejamento estratégico participaram catorze pessoas e ao concluir as etapas do planejamento, foi solicitado aos participantes que respondessem um questionário sobre a abordagem usada, tendo um percentual de resposta de $86 \%$. As pessoas que participaram esperam grandes benefícios com a execução do planejamento realizado, talvez até por já perceberem a tomada de decisões importantes durante a elaboração do planejamento estratégico. Quanto à metodologia usada, a seqüência dos passos e o instrumento de apoio, na percepção dos participantes, se mostraram adequados. Segundo os participantes, o uso da metodologia para orientar as etapas e as informações que deveriam ser descritas facilitou o planejamento estratégico, guiando as discussões.

Foram identificadas várias melhorias, tanto na abordagem proposta como no instrumento de apoio, dentre elas uma melhor descrição de cada etapa e orientação de como executá-la no instrumento para permitir o uso em outros contextos, pois neste caso, o autor da abordagem participou das reuniões e foi possível esclarecer dúvidas assim que surgiram, não impactando a elaboração do planejamento.

Com base nas experiências anteriores de alguns participantes, foi comentado que o uso de uma metodologia com um instrumento de apoio se mostrou bastante interessante facilitando as discussões e evitando longas reuniões para se chegar às definições. Também foi apontada como facilitadora, a infra-estrutura de apoio, por exemplo: projeção dos resultados de cada etapa, permitindo que todos visualizassem um único instrumento e opinassem inclusive sobre a redação de cada informação.

\section{Conclusão}

Este trabalho apresentou uma proposta para definição e monitoração de objetivos relacionados aos processos e produtos de software, denominados objetivos de software, alinhados aos objetivos de negócio de uma organização. A abordagem apóia o passo a passo desde a elaboração do planejamento estratégico até o controle estatístico dos processos e medição de software durante a execução dos projetos. Espera-se que a definição de objetivos de software que atendam às necessidades de negócio da organização e o uso desses objetivos para orientar as melhorias de software, inclusive a implantação de processos de alta maturidade através do controle estatístico dos processos, possam contribuir para o sucesso na implantação das melhorias. 
O planejamento do controle estatístico dos processos alinhado aos objetivos de negócio da organização proposto neste trabalho faz parte de um conjunto de pesquisas relacionadas a práticas de alta maturidade que vêm sendo feitas na COPPE/UFRJ. O desenvolvimento de uma infra-estrutura de apoio à execução desta abordagem incluindo ferramentas de apoio à definição e à monitoração automatizada dos objetivos definidos, e o uso desta abordagem em outras organizações são perspectivas futuras deste trabalho.

\section{Referências}

Audy, J.L.N. (2000), Modelo de Planejamento Estratégico de Sistemas de Informação: Contribuições da Aprendizagem Organizacional e do Processo Decisório, in Escola de Administração, Programa de Pós-Graduação em Administração, Tese de D.Sc., Escola de Administração, PPGA, UFRGS, Porto Alegre, Brasil.

Basili, V.R., Caldiera, G., Rombach, H. (1994), "Goal Question Metric Paradigm", In: Encyclopedia of Software Engineering, v. 1, John Wiley \& Sons. p. 528-532.

Basili, V.R. et al. (2007), GQM Strategies - Aligning Business Strategies with Software Measurement, In: $1^{\text {st }}$ International Symposium on Empirical Software Engineering and Measurement, Madrid, Spain.

Becker, A.L., Prikladnicki, R., Audy, J.L.N. (2008), "Strategic Alignment of Software Process Improvement Programs Using QFD”, In: $1^{\text {st }}$ International Workshop on Business Impact of Process Improvements, pp. 9-14, Leipzig, Germany, May.

Chiavenato, I. (2000), Administração: Teoria, Processo e Prática, SP, MakronBooks.

Chrissis, M.B., Konrad, M., Shrum, S. (2006), CMMI: Guidelines for Process Integration and Product Improvement, $2^{\text {nd }}$ ed., Nova York, USA, Addison-Wesley.

Conradi, R., Fuggetta, A. (2002), "Improving Software Process Improvement", IEEE Software, v. 19, n. 4, pp. 92-99.

IT Governance Institute (2007), "Control Objectives for Information and Related Technology”, $4.1^{\text {th }}$ edition, http://www.itgi.org.

Kaplan, R.S., Norton, D.P. (1996), The Balanced Scorecard Translating Strategy Into Action, Havard Business School Press.

Park, R.E., Goethert, W.B., Florac, W.A. (1996), Goal-Driven Software Measurement - A Guidebook, Carnegie Mellon University, Pittsburgh, PA, CMU/SEI-96-HB-002.

Ren, C. et al. (2006), "Linking Strategic Objectives to Operations: Towards a more Effective Supply Chain Decision Making”, In: Winter Simulation Conference, pp. 1422-1430, Monterey, California, USA, December.

Rezende D.A., Abreu, A.F. (2001), Tecnologia da Informação Aplicada a Sistemas de Informação Empresariais: O papel estratégico da informação e dos Sistemas de Informação nas empresas, 2 ed. São Paulo, Atlas.

Softex (2007), "MPS.BR - Melhoria de Processo do Software Brasileiro, Guia Geral", v1.2, SOFTEX - Associação para Promoção da Excelência do Software Brasileiro.

Wang, Q. et al. (2006), "BSR: A Statistical-Based Approach for Establishing and Refining Software Process Performance Baseline”, In: $28^{\text {th }}$ International Conference on Software Engineering, pp. 585-594, Shanghai, China, May. 